\title{
Recent trends in biodiesel production from commonly used animal fats
}

\begin{abstract}
Changes in climate due to the enormous amount of carbon dioxide emissions have really encouraged the development of energy sources that are renewable, sustainable, and ecofriendly. The development of alternative energy sources can also be attributed to the rapid decrease in resources of fossil energy. Biodiesel has gained significant interest in recent years due to its fossil fuel-like properties and sustainable and eco-friendly characteristics. However, most biodiesels are expensive because of the high cost of feedstock largely based on edible vegetable oil sources. The use of animal fats waste as cost effective feedstock in biodiesel production has gained considerable attention in recent years. Although, most studies regarding the use of animal wastes as feedstock in biodiesel production are still in the early stages, the advantages of this type of feedstock have been highlighted in the literature. However, most studies have not focus on the recent advances in the use of animal fats waste. The studies on the use of novel approach have been reported in isolation. Therefore, this current study attempts to highlight recent developments of the most commonly used animal fats waste in the production of biodiesel. In addition, emphasis was given to the most appropriate production technique, catalyst, energy requirement, and optimum reaction conditions.
\end{abstract}

